\title{
Effect of Lumen Narrowing Within Sirolimus-Eluting Stents on Proximal and Distal Vessel Segments
}

\author{
Katsuhisa Waseda, MD, PhD; Junya Ako, MD; Hideaki Kaneda, MD, PhD; \\ Akiyoshi Miyazawa, MD; Yoshihisa Shimada, MD, PhD; Yoshihiro Morino, MD; \\ Yasuhiro Honda, MD; Peter J. Fitzgerald, MD, PhD
}

\begin{abstract}
Background Flow dynamics and shear stress may influence downstream vessel segments. The aim of this study was to investigate the potential impact of lumen narrowing within sirolimus-eluting stents (SES) on vessel response at adjacent reference sites.

Methods and Results In 135 patients after SES implantation, minimal lumen area (MLA) within the stent and average lumen area at distal or proximal adjacent reference segments $(5 \mathrm{~mm})$ were obtained at baseline and follow up. In the smaller in-stent MLA group $\left(M L A<3 \mathrm{~mm}^{2}\right)$, lumen area decreased significantly at the distal reference compared with the larger in-stent MLA group (MLA $\geq 3 \mathrm{~mm}^{2}$ ), although no significant difference was seen at the proximal reference.
\end{abstract}

Conclusion In-stent lumen patency may influence vascular responses at adjacent reference segments after SES implantation. (Circ J 2008; 72: 534-537)

Key Words: Coronary artery disease; Intravascular ultrasound; Stents

$\mathbf{F}$ low dynamics and shear stress may influence the vessel response following stent implantation!,2 Maintaining luminal dimension within stents has been shown to influence vessel response outside the stents, especially at the distal reference segments? Sirolimuseluting stents (SES) have demonstrated excellent mid-term results through their ability to maintain larger luminal dimensions inside the stents, 4 .5 However, relatively there are few studies on the effect of luminal dimension on the vessel response in adjacent stent segments following drugeluting stents.

Thus, the aim of the present study was to examine the effect of a smaller lumen at a stented segment on vessel responses of adjacent reference segments after SES implantation, using serial 3-dimensional (D) intravascular ultrasound (IVUS) analysis.

\section{Methods}

\section{Study Population}

The IVUS database of the Cardiovascular Core Analysis Laboratory at Stanford University (Stanford, CA, USA) was searched to identify patients who met the following criteria: (1) successful treatment with SES using standard stent implantation techniques without atheroablation; (2) complete serial (baseline and at 6- to 8-months mandated follow up) IVUS studies; and (3) high-quality, automated

(Received July 1, 2007; revised manuscript received November 2, 2007; accepted November 27, 2007)

Center for Research in Cardiovascular Interventions, Stanford University Medical Center, Stanford, CA, USA

Mailing address: Peter J. Fitzgerald, MD, PhD, Center for Research in Cardiovascular Interventions, Stanford University Medical Center, 300 Pasteur Drive, Room H3554, Stanford, CA 94305-5637, USA. E-mail: crci-cvmed@stanford.edu

All rights are reserved to the Japanese Circulation Society. For permissions, please e-mail: cj@j-circ.or.jp pull-back IVUS images within stented segments and up to $5 \mathrm{~mm}$ at adjacent segments outside each stent edge. A total of 135 patients met the enrolment criteria. The protocol was approved by the institutional review board, and written informed consent was obtained from each patient.

\section{IVUS Analysis}

IVUS was performed in a standard fashion at baseline and at 6- to 8-months follow up, using a single-element mechanical ultrasound catheter $(40 \mathrm{MHz}$; Boston Scientific Corp, Natick, MA, USA). As per protocol, intracoronary nitroglycerin was injected before image acquisition, with motorized pull-back devices $(0.5 \mathrm{~mm} / \mathrm{s})$ used during all IVUS data acquisitions. All IVUS images were recorded on s-VHS videotape for off-line analysis. Lumen and external elastic membrane (vessel) areas were traced manually at every $0.5-\mathrm{mm}$ interval in adjacent reference segments ( $>5 \mathrm{~mm}$ long) and stented segments. Using Simpson's method, lumen, vessel and plaque (vessel minus lumen) volumes were calculated, and average area (volume index) was calculated as volume data divided by length. The change in each parameter was calculated as follow-up minus baseline. Maximum cross-sectional narrowing (\%) was defined as neointimal area divided by stent area. To evaluate the effect of decreased lumen, patients were categorized into 2 groups according to minimal lumen area (MLA) within the stent at follow up (ie, MLA $<3$ or $\geq 3 \mathrm{~mm}^{2}$ )

\section{Statistical Analysis}

Data are presented as the mean $\pm \mathrm{SD}$ or frequencies. Statistical analysis was performed with StatView 5.0 (SAS Institute, Cary, NC, USA). Group comparisons were performed using unpaired Student's t-test for continuous variables, and chi-squared test for categorical variables. A p-value of $<0.05$ was considered statistically significant. Multiple regression analysis included parameters of $\mathrm{p}$-value $<0.05$ by univariate analysis. 
Table 1 Clinical and Procedural Characteristics

\begin{tabular}{|c|c|c|c|}
\hline & $\begin{array}{c}M L A<3 \mathrm{~mm}^{2} \text { within stent } \\
(n=20)\end{array}$ & $\begin{array}{c}M L A \geq 3 m^{2} \text { within stent } \\
(n=115)\end{array}$ & $p$ value \\
\hline Age (years) & $62 \pm 11$ & $60 \pm 10$ & 0.452 \\
\hline Male gender $(\%)$ & 65 & 75 & 0.343 \\
\hline \multicolumn{4}{|l|}{ Coronary risk factors (\%) } \\
\hline Diabetes mellitus & 25 & 31 & 0.611 \\
\hline Hyperlipidemia & 80 & 81 & 0.902 \\
\hline Hypertension & 65 & 68 & 0.794 \\
\hline Current smoker & 58 & 36 & 0.068 \\
\hline \multicolumn{4}{|l|}{ Angina type } \\
\hline Unstable angina $(\%)$ & 15 & 27 & 0.275 \\
\hline Prior $\mathrm{PCI}(\%)$ & 18 & 29 & 0.328 \\
\hline Prior myocardial infarction (\%) & 45 & 38 & 0.536 \\
\hline \multicolumn{4}{|l|}{ Treated vessel (\%) } \\
\hline Right & 5 & 32 & $<0.05$ \\
\hline Left anterior descending & 25 & 41 & \\
\hline Left circumflex & 70 & 27 & \\
\hline Stent length $(\mathrm{mm})$ & $22 \pm 6$ & $21 \pm 5$ & 0.484 \\
\hline
\end{tabular}

$M L A$, minimal lumen area; PCI, percutaneous coronary intervention.

Table 2 In-Stent IVUS Analysis Results

\begin{tabular}{lccc}
\hline \hline & $M L A<3 \mathrm{~mm}^{2}$ within stent & $M L A \geq 3 \mathrm{~mm}^{2}$ within stent & $p$ value \\
\hline Baseline & & & \\
Vessel $V I\left(\mathrm{~mm}^{3} / \mathrm{mm}\right)$ & $8.6 \pm 2.0$ & $13.1 \pm 4.8$ & $<0.001$ \\
Lumen $V I\left(\mathrm{~mm}^{3} / \mathrm{mm}\right)$ & $4.1 \pm 0.7$ & $6.4 \pm 2.3$ & $<0.001$ \\
MLA $\left(\mathrm{mm}^{2}\right)$ & $3.3 \pm 0.8$ & $5.4 \pm 2.1$ & $<0.001$ \\
Follow up & $8.7 \pm 1.9$ & $13.6 \pm 4.5$ & $<0.001$ \\
Vessel $V I\left(\mathrm{~mm}^{3} / \mathrm{mm}\right)$ & $3.9 \pm 0.6$ & $6.5 \pm 2.3$ & $<0.001$ \\
Lumen $\mathrm{VI}\left(\mathrm{mm}^{3} / \mathrm{mm}\right)$ & $0.2 \pm 0.4$ & $0.1 \pm 0.2$ & 0.09 \\
Neointima $\mathrm{VI}\left(\mathrm{mm}^{3} / \mathrm{mm}\right)$ & $28.2 \pm 17.7$ & $13.5 \pm 11.4$ & $<0.001$ \\
Max. CSN $(\%)$ & $2.5 \pm 0.4$ & $5.2 \pm 2.1$ & $<0.001$ \\
MLA $\left(\mathrm{mm}^{2}\right)$ & $0.7 \pm 1.0$ & $0.1 \pm 0.7$ & $<0.01$ \\
Late area loss $\left(\mathrm{mm}^{2}\right)$ & &
\end{tabular}

IVUS, intravascular ultrasound; VI, volume index; CSN, cross-sectional narrowing. Other abbreviation see in Table 1.

\section{Results}

Baseline clinical and procedural characteristics were not significantly different between the 2 groups, except for treated vessel (Table 1). Follow-up volumetric IVUS at the stented segment showed smaller lumen areas $(3.9 \pm 0.6$ vs $\left.6.5 \pm 2.3 \mathrm{~mm}^{3} / \mathrm{mm} ; \mathrm{p}<0.001\right)$ and stent areas $(4.1 \pm 0.8 \mathrm{vs}$ $6.6 \pm 2.3 \mathrm{~mm}^{3} / \mathrm{mm} ; \mathrm{p}<0.001$ ), and a larger mean neointimal area in the smaller in-stent MLA group (Table 2). In the smaller in-stent group, lumen area decreased significantly at the distal reference compared with that in the larger instent MLA group $\left(-0.5 \pm 0.9\right.$ vs $\left.0.0 \pm 1.0 \mathrm{~mm}^{3} / \mathrm{mm} ; \mathrm{p}<0.05\right)$, whereas no significant difference was seen at the proximal stent reference (Fig 1). There was a trend toward greater negative remodeling in the smaller in-stent MLA group at the distal reference $\left(-0.4 \pm 1.1\right.$ vs $\left.0.2 \pm 1.3 \mathrm{~mm}^{3} / \mathrm{mm} ; \mathrm{p}=0.08\right)$. Analysis using continuous variables also showed a mild correlation between in-stent MLA at follow up and lumen area loss at the distal reference $(\mathrm{r}=0.182 ; \mathrm{p}=0.037)$. Additional multiple regression analysis, including vessel and lumen area at baseline, in-stent MLA at baseline and follow-up, and target vessel, confirmed in-stent MLA at follow up as an independent determinant of lumen area loss at the distal reference $(\mathrm{p}=0.0009)$.

\section{Discussion}

The present study demonstrated that luminal narrowing within the stent affects vessel response at the distal adjacent reference segment after SES implantation. These results confirm the findings of similar effects observed in baremetal stents?

The vessel response in adjacent segment after stenting yields complex findings. Serial IVUS studies of bare-metal stents have reported that lumen loss at the proximal segment is primarily due to negative remodeling ${ }^{7}$ or plaque accumulation? Another report has shown luminal loss in the distal reference segment is primarily due to plaque gain and negative remodeling $2 \mathrm{~mm}$ beyond the stent edge? Decreased shear stress, resulting from decreased flow, induces a decrease in internal vessel diameters? 210 Atherosclerotic lesions co-localize with regions of low shear stress throughout the arterial tree. Low wall shear stress is an important contributor to conditions that favor atherogenic transformation! In the present study, stent patency or maintaining proximal laminar flow at the time of follow-up had an effect on vascular responses distal to the stent. Larger luminal dimensions within the stents can help maintain the blood flow and shear stress distal to the stented segment, possibly contributing to the reduced luminal loss seen at the distal adjacent segment.

Several drug-eluting stent trials have shown a potential beneficial effect of these stents on distal reference segments compared with bare-metal stents ${ }^{1-15}$ However, in a porcine coronary model of SES implantation, arterial tissue adjacent to the stent-implanted vessel contained much less 

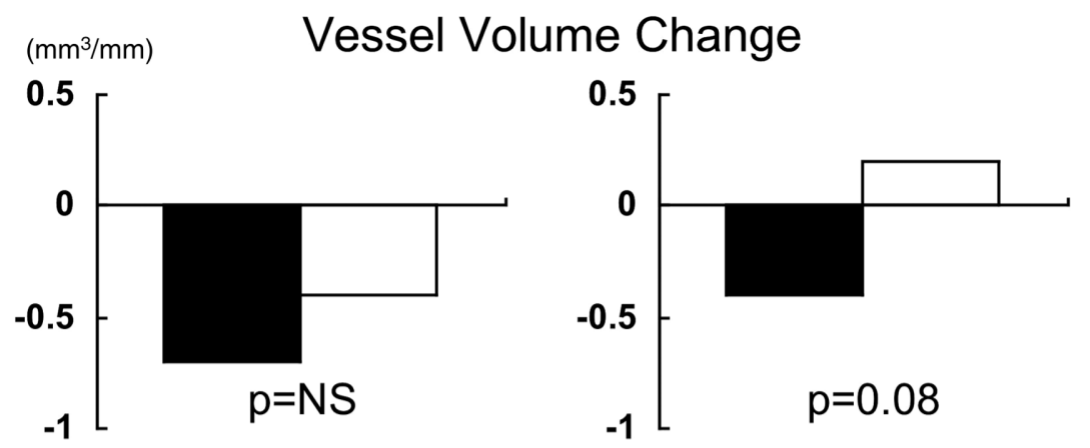

Plaque Volume Change
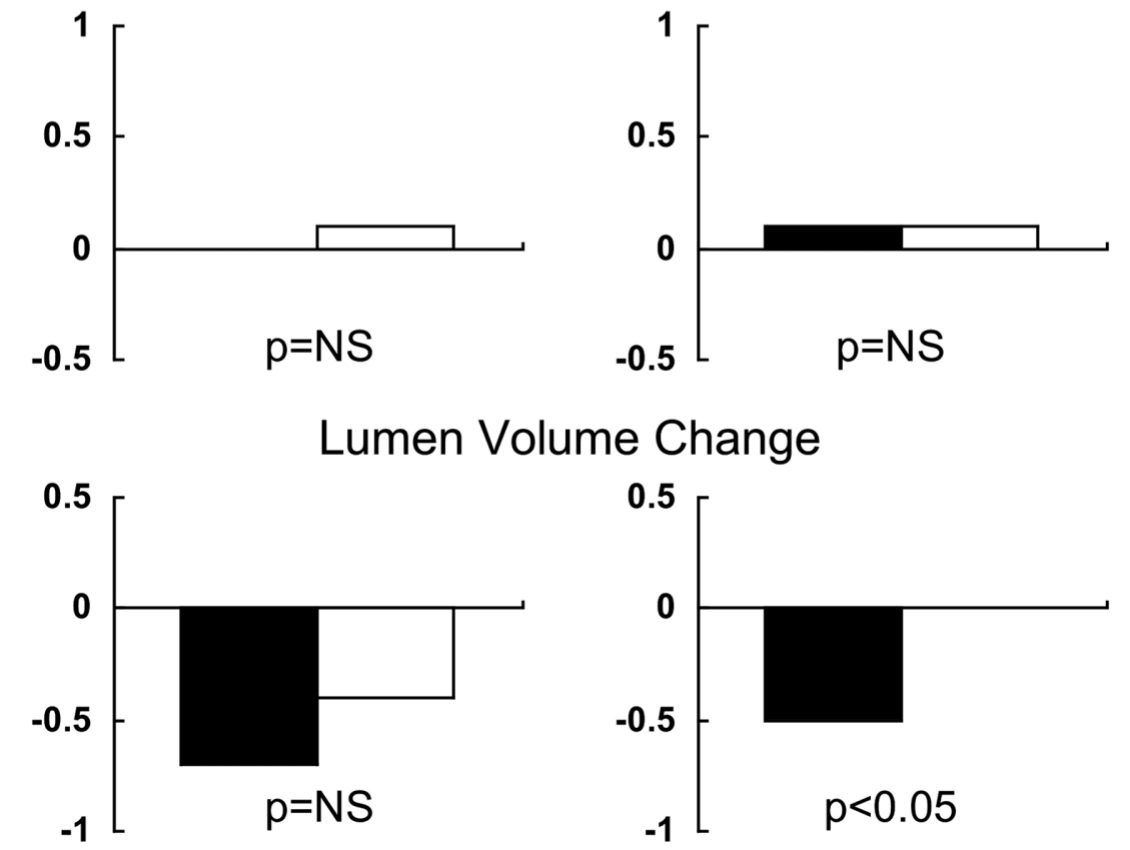

Fig 1. Effect of minimal lumen area (MLA) within the stent on changes in vessel, plaque, and lumen volume index at proximal (Left) and distal (Right) adjacent reference segments. In the smaller MLA group (MLA $<3 \mathrm{~mm}^{2}$ ) (black columns), lumen volume index significantly decreased at distal reference compared with that in the larger MLA group (MLA $\geq 3 \mathrm{~mm}^{2}$ ) (white columns) $(\mathrm{p}<0.05$ ), although no significant difference was observed at the proximal reference. NS, not significant.

sirolimus $(2 \%)$ compared with the stented segment 16 Furthermore, our previous clinical study with bare-metal stents demonstrated similar observations to the results of the present study? Combined with the consistently favorable reference vessel responses observed with different agents and different delivery systems, stent patency itself, rather than the drug uptake in arterial tissue, may play a role in the distal reference vessel response observed after drugeluting stent implantation.

Luminal dimension is an important determinant for short- and mid-term safety, including stent thrombosis, and mid-term patency following SES implantation.17,18 The present study has shown that luminal dimension within the stent is an important determinant in the long-term maintenance of the vessel size distal to the stented segment. Although smaller post-stent luminal dimension can achieve adequate long-term patency with drug-eluting stents, ${ }^{19}$ optimal expansion may still be important in light of the longterm vessel response following SES implantation.

The results of the present study may also provide potentially important clinical implications regarding treatment of complex lesion subsets. Recent clinical observations have shown a possible benefit in using drug-eluting stents for the treatment of chronic total occlusions. ${ }^{20,21}$ Adequate antegrade coronary flow may be beneficial in maintaining vessel dimensions in the distal segment in long-term follow up.

\section{Study Limitations}

Several limitations should be noted. First, this is a retrospective study based on a relatively limited sample size, raising the possibility of selection bias. Second, the followup period of the present study was limited to 6-8 months. Longer-term results of the findings are still an open discussion, and further observation may be required to clarify their impact on clinical outcomes. Third, there are several inherent limitations in 3-D analysis techniques, including the effects of movement artifact and distortion due to curvature of the vessels.22 Finally, in vivo assessment of flow dynamics and shear stress within coronary arteries is currently limited in conventional coronary imaging techniques. A combination of angiography and IVUS for spatially correct 3-D reconstruction may provide a further insight into the direct mechanism of these observations.

\section{Conclusion}

In-stent lumen patency may influence vascular responses at adjacent reference segments after SES implantation. Optimal geometry within the stent may be important in maintaining vascular dimensions distal to the stented segment. 


\section{Acknowledgment}

The authors thank Heidi N. Bonneau, RN, MS, for her expert review of this manuscript.

\section{References}

1. Malek AM, Alper SL, Izumo S. Hemodynamic shear stress and its role in atherosclerosis. JAMA 1999; 282: 2035-2042.

2. Richter Y, Edelman ER. Cardiology is flow. Circulation 2006; 113: 2679-2682

3. Kaneda H, Ako J, Kataoka T, Miyazawa A, Terashima M, Ikeno F, et al. Effect of lumen narrowing within coronary stents on proximal and distal vessel segments following bare metal stent implantation. Am J Cardiol 2005; 96: 376-378.

4. Nakazawa G, Tanabe K, Aoki J, Onuma Y, Yamamoto H, Higashikuni $\mathrm{Y}$, et al. Clinical and angiographic outcomes of sirolimus-eluting stents implantation in Japanese patients in daily practice. Circ J 2006; 70: $1367-1371$.

5. Suzuki S, Kamihata H, Hata T, Hayashi F, Miura A, Yoshinaga M, et al. Success rate of implantation and mid-term outcomes of the sirolimus-eluting stent. Circ J 2007; 71: 15-19.

6. Takagi A, Tsurumi Y, Ishii Y, Suzuki K, Kawana M, Kasanuki H Clinical potential of intravascular ultrasound for physiological assessment of coronary stenosis: Relationship between quantitative ultrasound tomography and pressure-derived fractional flow reserve. Circulation 1999; 100: 250-255.

7. Hoffmann R, Mintz GS, Dussaillant GR, Popma JJ, Pichard AD, Satler LF, et al. Patterns and mechanisms of in-stent restenosis: A serial intravascular ultrasound study. Circulation 1996; 94: 1247 1254.

8. Mudra H, Regar E, Klauss V, Werner F, Henneke KH, Sbarouni E, et al. Serial follow-up after optimized ultrasound-guided deployment of Palmaz-Schatz stents: In-stent neointimal proliferation without significant reference segment response. Circulation 1997; 95: $363-$ 370 .

9. Weissman NJ, Wilensky RL, Tanguay JF, Bartorelli AL, Moses J, Williams DO, et al. Extent and distribution of in-stent intimal hyperplasia and edge effect in a non-radiation stent population. Am J Cardiol 2001; 88: 248-252.

10. Langille BL, O'Donnell F. Reductions in arterial diameter produced by chronic decreases in blood flow are endothelium-dependent. Science 1986; 231: 405-407.

11. Colombo A, Drzewiecki J, Banning A, Grube E, Hauptmann K, Silber S, et al. Randomized study to assess the effectiveness of slowand moderate-release polymer-based paclitaxel-eluting stents for coronary artery lesions. Circulation 2003; 108: 788-794.
12. Kataoka T, Grube E, Honda Y, Morino Y, Hur SH, Bonneau HN, et al. 7-Hexanoyltaxol-eluting stent for prevention of neointimal growth: An intravascular ultrasound analysis from the Study to COmpare REstenosis rate between QueST and QuaDS-QP2 (SCORE). Circulation 2002; 106: 1788-1793.

13. Morice MC, Serruys PW, Sousa JE, Fajadet J, Ban Hayashi E, Perin $\mathrm{M}$, et al. A randomized comparison of a sirolimus-eluting stent with a standard stent for coronary revascularization. N Engl J Med 2002; 346: $1773-1780$.

14. Moses JW, Leon MB, Popma JJ, Fitzgerald PJ, Holmes DR, O'Shaughnessy C, et al. Sirolimus-eluting stents versus standard stents in patients with stenosis in a native coronary artery. $N$ Engl J Med 2003; 349: 1315-1323.

15. Serruys PW, Degertekin M, Tanabe K, Russell ME, Guagliumi G, Webb J, et al. Vascular responses at proximal and distal edges of paclitaxel-eluting stents: Serial intravascular ultrasound analysis from the TAXUS II trial. Circulation 2004; 109: 627-633.

16. Ikeno F, Bailey L, Willard C, Kopia GA, Tio F, Dooley J. Sirolimuseluting stents: Pharmacokinetics in blood, vessel, and myocardium in a porcine coronary model. J Am Coll Cardiol 2004; 43: 83A.

17. Fujii K, Carlier SG, Mintz GS, Yang YM, Moussa I, Weisz G, et al. Stent underexpansion and residual reference segment stenosis are related to stent thrombosis after sirolimus-eluting stent implantation: An intravascular ultrasound study. J Am Coll Cardiol 2005; 45: 995-998.

18. Fujii K, Mintz GS, Kobayashi Y, Carlier SG, Takebayashi H, Yasuda $\mathrm{T}$, et al. Contribution of stent underexpansion to recurrence after sirolimus-eluting stent implantation for in-stent restenosis. Circulation 2004; 109: 1085-1088.

19. Sonoda S, Morino Y, Ako J, Terashima M, Hassan AH, Bonneau $\mathrm{HN}$, et al. Impact of final stent dimensions on long-term results following sirolimus-eluting stent implantation: Serial intravascular ultrasound analysis from the sirius trial. J Am Coll Cardiol 2004; 43: 1959-1963.

20. Buellesfeld L, Gerckens U, Mueller R, Schmidt T, Grube E. Polymerbased paclitaxel-eluting stent for treatment of chronic total occlusions of native coronaries: Results of a Taxus CTO registry. Catheter Cardiovasc Interv 2005; 66: $173-177$.

21. Hoye A, Tanabe K, Lemos PA, Aoki J, Saia F, Arampatzis C, et al. Significant reduction in restenosis after the use of sirolimus-eluting stents in the treatment of chronic total occlusions. J Am Coll Cardiol 2004; 43: 1954-1958.

22. de Vrey EA, Mintz GS, von Birgelen C, Kimura T, Noboyoshi M, Popma JJ, et al. Serial volumetric (three-dimensional) intravascular ultrasound analysis of restenosis after directional coronary atherectomy. J Am Coll Cardiol 1998; 32: 1874-1880. 